\title{
Animal sources for zoonotic transmission of psittacosis: a systematic review
}

Lenny Hogerwerf $^{1 \dagger}$, Inge Roof ${ }^{1_{+}+}$(D) Marianne J. K. de Jong ${ }^{1,2}$, Frederika Dijkstra ${ }^{1}$ and Wim van der Hoek ${ }^{1}$

\begin{abstract}
Background: Human psittacosis, caused by Chlamydia (C.) psittaci, is likely underdiagnosed and underreported, since tests for $C$. psittaci are often not included in routine microbiological diagnostics. Source tracing traditionally focuses on psittacine pet birds, but recently other animal species have been gaining more attention as possible sources for human psittacosis. This review aims to provide an overview of all suspected animal sources of human psittacosis cases reported in the international literature. In addition, for each animal species the strength of evidence for zoonotic transmission was estimated.

Methods: A systematic literature search was conducted using four databases (Pubmed, Embase, Scopus and Proquest). Articles were included when there was mention of at least one human case of psittacosis and a possible animal source. Investigators independently extracted data from the included articles and estimated strength of evidence for zoonotic transmission, based on a self-developed scoring system taking into account number of human cases, epidemiological evidence and laboratory test results in human, animals, and the environment.

Results: Eighty articles were included, which provided information on 136 different situations of possible zoonotic transmission. The maximum score for zoonotic transmission was highest for turkeys, followed by ducks, owls, and the category 'other poultry'. Articles reporting about zoonotic transmission from unspecified birds, psittaciformes and columbiformes provided a relatively low strength of evidence. A genotypical match between human and animal samples was reported twenty-eight times, including transmission from chickens, turkeys, guinea fowl, peafowl, pigeons, ducks, geese, songbirds, parrot-like birds and owls.
\end{abstract}

Conclusions: Strong evidence exists for zoonotic transmission from turkeys, chickens and ducks, in addition to the more traditionally reported parrot-like animal sources. Based on our scoring system, the evidence was generally stronger for poultry than for parrot-like birds. Psittaciformes should not be disregarded as an important source of human psittacosis, still clinicians and public health officials should include poultry and birds species other than parrots in medical history and source tracing.

Keywords: Psittacosis, Chlamydia psittaci, Zoonosis, Animal sources, Strength of evidence

\footnotetext{
* Correspondence: inge.roof@rivm.nl

†Lenny Hogerwerf and Inge Roof contributed equally to this work.

${ }^{1}$ Centre for Infectious Disease Control, National Institute for Public Health and the Environment, Bilthoven, the Netherlands

Full list of author information is available at the end of the article
}

(c) The Author(s). 2020 Open Access This article is licensed under a Creative Commons Attribution 4.0 International License, which permits use, sharing, adaptation, distribution and reproduction in any medium or format, as long as you give appropriate credit to the original author(s) and the source, provide a link to the Creative Commons licence, and indicate if changes were made. The images or other third party material in this article are included in the article's Creative Commons licence, unless indicated otherwise in a credit line to the material. If material is not included in the article's Creative Commons licence and your intended use is not permitted by statutory regulation or exceeds the permitted use, you will need to obtain permission directly from the copyright holder. To view a copy of this licence, visit http://creativecommons.org/licenses/by/4.0/ The Creative Commons Public Domain Dedication waiver (http://creativecommons.org/publicdomain/zero/1.0/) applies to the data made available in this article, unless otherwise stated in a credit line to the data. 


\section{Background}

Psittacosis is a zoonosis caused by the bacterium Chlamydia (C.) psittaci. Transmission occurs mainly by inhalation of the agent, which is excreted by birds in feces and in droplets from the respiratory tract $[1,2]$. In the 1930s, major outbreaks of psittacosis occurred worldwide, caused by trade of parrots and other tropical birds. These outbreaks are even referred to as 'the psittacosis pandemic' [3-5]. In 1985, an outbreak of psittacosis affected employees at a duck processing plant in the United Kingdom [6]. Nowadays psittacosis cases are usually limited to local outbreaks, small clusters or isolated cases [7-17]. Community-acquired pneumonia (CAP) is the most important presentation of human psittacosis, but microbiological testing for psittacosis in a pneumonia patient is often not incorporated in routine diagnostics. Due to the non-specific symptoms and the fact that often only severely ill patients are being tested for $C$. psittaci, the disease is likely underdiagnosed and underreported [18-22]. A recent review and meta-analysis of CAP etiological studies estimated that in 1.03\% (95\% CI: 0.79-1.30) of all CAP cases from the included studies combined, $C$. psittaci was the causative pathogen, with a range between studies from 0 to $6.7 \%$ [21]. Based on this result, an estimated $4.4 \%$ (95\% CI: $1.6-8.2 \%$ ) of symptomatic cases were notified in the Netherlands over the period 2012-2014 [20]. Human psittacosis is mostly linked to parrots or ornamental birds as source of infection, however, recently other bird and animal species have been gaining more attention as potential sources of human psittacosis, such as poultry species, pigeons and even mammals [23-26]. To inform clinicians, public health officials and people at risk of exposure to potentially infected animals, we reviewed animal sources that have been associated with human psittacosis in the recent international literature and provided strength of evidence for zoonotic transmission for each of the animal categories.

\section{Methods}

\section{Search strategy}

A literature search of studies describing human cases of psittacosis with an associated animal source was conducted. The databases Pubmed, Embase, Scopus and Proquest (CAB Abstracts and BIOSIS Previews) were searched using the following terms and synonyms hereof: psittacosis, Chlamydia or Chlamydophila psittaci, psittaci, ornithosis, human, patient and zoonosis. Studies were included from 1 January 2000 to 27 June 2018, because of the major adjustments in taxonomy and nomenclature from the year 1999 [27]. Languages were restricted to Dutch, German, Spanish, French, Portuguese and English. No limitations were applied regarding the study design. The search results from all databases were merged into one EndNote X8 file and removal of duplicates was performed using EndNote and by hand.

\section{In- and exclusion criteria}

Titles and abstracts were screened by two investigators (IR and MdJ) and records were included when there was mention of at least one human case of psittacosis and a possible animal source. Records without abstract were included based on relevance of the title. Reports mentioning only animal sources without human cases were excluded. Full-text assessment was performed by two investigators (IR and MdJ) and uncertainties about article inclusion were discussed with other authors (FD, LH or WvdH). Exclusion criteria during full-text assessment were: no laboratory confirmed human cases, no animal source, no specification of animal exposure (e.g. animal, pet, zoo, veterinarian), review articles, guidelines, articles presenting unoriginal data (e.g. mentioning identical cases and identical associated animal sources as previously reported without additional evidence), human psittacosis due to Chlamydia species other than C. psittaci and language other than Dutch, Spanish, French, Portuguese, English or German. Reference lists of included full-text articles were screened by hand for additional titles.

\section{Data extraction}

Four investigators (IR, LH, MdJ and WvdH) independently extracted the following data from the included articles: year and country of human cases, animal species, number of human cases, contact of human case with sick animal, type of diagnostics used in humans/animals with associated results, genotyping results in humans/animals, environmental investigation and epidemiological evidence. Any disagreement was resolved through discussion and consensus. During data extraction the rationale and definitions of the original authors were followed. The total number of confirmed human cases was defined by adding the number of probable cases (according to the original author's definition of a probable case) and the number of confirmed human cases with a positive laboratory result. We did not specify criteria for laboratory results because there is a wide variety in criteria for confirmation of a human case in the literature. Analysis of animal faecal samples was considered as environmental investigation. Epidemiological evidence was confirmed when a study demonstrated an increased risk of human psittacosis by the animal species involved. When studies reported multiple situations of zoonotic transmission with different animal sources or when cases had multiple associated animal exposures, the animal species were entered in separate lines under the same study. In addition, studies reporting multiple unrelated cases were also entered separately. Bird 
species were categorized according to their order in the bird taxonomy (e.g. psittaciformes, passeriformes, columbiformes etc.). Poultry species were separated into the categories chicken, duck, turkey and other poultry. Situations reporting on bird or poultry species without further specification were included under the category 'unspecified birds' or 'unspecified poultry' respectively.

\section{Calculation strength of evidence}

Strength of evidence for zoonotic transmission was calculated based on a scoring system using the following factors (weight between brackets): number of confirmed human cases above the overall median number calculated across the included studies (2); positive antibody test in humans (1) or animals (1); detection of antigen in humans (2) or animals (2); genotyping results in humans (2) or animals (2); contact with sick animal (2); environmental sample positive for C. psittaci antigen (2); genotyping of environmental sample (2); epidemiological evidence (4); genotypical match between human and animal species category (8), genotypical mismatch between human and animal species category (set final score to 0 ). The strength of evidence score was calculated per animal species per study or per animal species for each separate case when a study reported multiple unrelated cases.

\section{Results}

\section{Inclusion of articles}

The search strategy yielded 2502 articles from four databases, of which 1201 were unique and screened for eligibility on title and abstract. Of all 138 articles included in the full-text screening, the full-text could be retrieved. Two additional records were found by screening the reference lists of included full-text articles. In total, 80 articles met the criteria for final inclusion in this review (Fig. 1). No quality assessment of study design was performed, because the majority of studies were case reports.

\section{Characteristics of included articles}

The selected 80 articles described 136 associations of human psittacosis cases with an animal source (Table 1). The largest number of articles originated from Belgium (23\%), the Netherlands (10\%) and France (10\%). Thirteen studies were cross-sectional or seroprevalence studies, investigating the prevalence of C. psittaci infection in high-risk groups and animals,

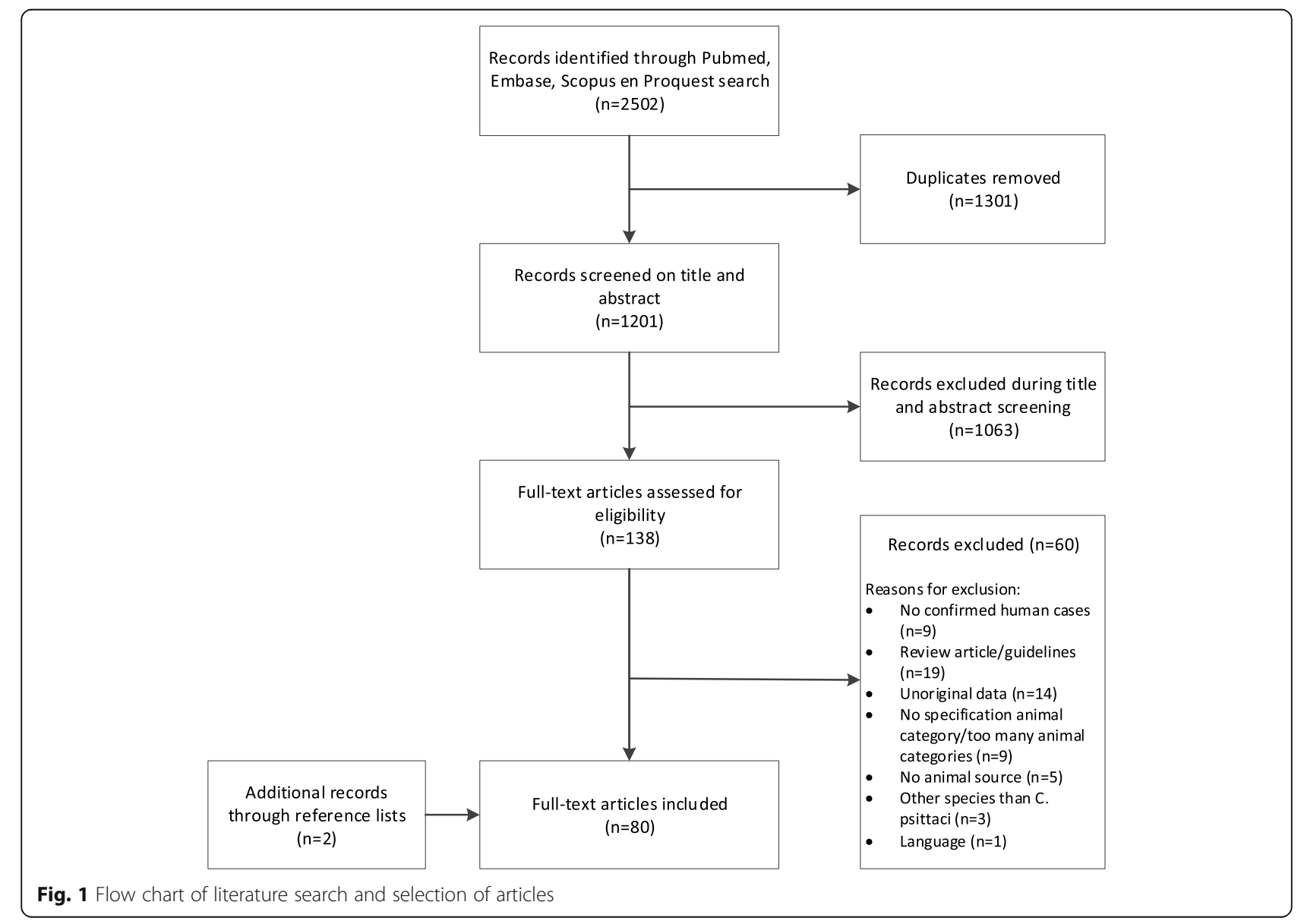


Table 1 Included studies describing human psittacosis cases and associated animal sources with strength of evidence score

\begin{tabular}{|c|c|c|c|c|c|c|c|}
\hline Reference, year & Animal species & $\begin{array}{l}\text { Year of } \\
\text { notification }\end{array}$ & Country & Diagnostics human & $\begin{array}{l}\text { No. confirmed } \\
\text { human cases }\end{array}$ & $\begin{array}{l}\text { Diagnostics animal } \\
\text { and/or environment }\end{array}$ & $\begin{array}{l}\text { Strength of } \\
\text { evidence }\end{array}$ \\
\hline \multirow{3}{*}{$\begin{array}{l}\text { Abadia et al., } 2006 \\
\text { [28] }\end{array}$} & ducks & 2000 & France & serology & $71^{\mathrm{b}}$ & no & 8 \\
\hline & chickens & 2000 & France & serology & $71^{b}$ & no & 4 \\
\hline & turkeys & 2000 & France & serology & $71^{b}$ & no & 4 \\
\hline $\begin{array}{l}\text { Arenas-Valls et al., } \\
2017 \text { [17] }\end{array}$ & psittaciformes & unknown & Spain & PCR \& serology & 4 & no & 8 \\
\hline Arraiz et al., 2012 [29] & columbiformes & unknown & Venezuela & $P C R$ & 8 & PCR & 19 \\
\hline $\begin{array}{l}\text { Belchior et al., } 2010 \\
\text { [30] }\end{array}$ & ducks & 2009 & France & PCR \& serology & 4 & no & 12 \\
\hline $\begin{array}{l}\text { Belchior et al., } 2011 \\
\text { [31] }\end{array}$ & unspecified birds & 2008 & France & PCR \& serology & 4 & $P C R$ & 8 \\
\hline Berk et al., 2008 [7] & passeriformes & 2007 & $\begin{array}{l}\text { The } \\
\text { Netherlands }\end{array}$ & PCR \& serology & 12 & antigen detection & 8 \\
\hline $\begin{array}{l}\text { Bourne et al., } 2003 \\
\text { [32] }\end{array}$ & psittaciformes & unknown & $\begin{array}{l}\text { United } \\
\text { Kingdom }\end{array}$ & serology & 1 & no & 2 \\
\hline $\begin{array}{l}\text { Branley et al., } 2008 \\
\text { [33] }\end{array}$ & psittaciformes & unknown & Australia & $\begin{array}{l}\text { PCR, culture \& } \\
\text { serology }\end{array}$ & 3 & PCR \& culture & 12 \\
\hline $\begin{array}{l}\text { Branley et al., } 2014 \\
\text { [34] }\end{array}$ & unspecified birds & 2003-2009 & Australia & $\begin{array}{l}\text { PCR, culture \& } \\
\text { serology }\end{array}$ & 48 & no & 6 \\
\hline \multirow{5}{*}{$\begin{array}{l}\text { Cadario et al., 2017 } \\
\text { [35] }\end{array}$} & chickens & 2010 & Argentina & PCR & 1 & no & 5 \\
\hline & psittaciformes & 2011 & Argentina & $P C R$ & 1 & PCR & 17 \\
\hline & psittaciformes & 2013 & Argentina & PCR & 1 & $P C R$ & 17 \\
\hline & columbiformes & 2013 & Argentina & $P C R$ & 1 & no & 5 \\
\hline & psittaciformes & 2014 & Argentina & PCR & 1 & no & 5 \\
\hline Carlier et al., 2014 [36] & ducks & 2011 & France & PCR \& serology & 1 & PCR & 10 \\
\hline Chan et al., 2017 [37] & horse & 2014 & Australia & serology & 3 & PCR \& serology & 15 \\
\hline \multirow[t]{4}{*}{ Chau et al., 2015 [38] } & psittaciformes & 2014 & Hong Kong & PCR \& serology & 1 & no & 4 \\
\hline & chickens & 2014 & Hong Kong & PCR \& serology & 1 & no & 4 \\
\hline & geese & 2014 & Hong Kong & PCR \& serology & $1^{b}$ & no & 4 \\
\hline & chickens & 2014 & Hong Kong & PCR \& serology & $1^{b}$ & no & 4 \\
\hline $\begin{array}{l}\text { Cheng et al., } 2013 \\
\text { [39] }\end{array}$ & psittaciformes & 2011 & Taiwan & serology & 1 & no & 4 \\
\hline Ciftci et al., 2008 [40] & psittaciformes & unknown & Turkey & serology & 2 & no & 2 \\
\hline $\begin{array}{l}\text { Clarence et al., } 2016 \\
\text { [41] }\end{array}$ & columbiformes & unknown & $\begin{array}{l}\text { United } \\
\text { Kingdom }\end{array}$ & $P C R$ & 1 & no & 5 \\
\hline $\begin{array}{l}\text { De Boeck et al., } 2016 \\
\text { [42] }\end{array}$ & psittaciformes & 2013 & Belgium & $\begin{array}{l}\text { PCR, culture \& } \\
\text { serology }\end{array}$ & 3 & $P C R$ & 22 \\
\hline $\begin{array}{l}\text { De Schrijver et al., } \\
2016 \text { [43] }\end{array}$ & psittaciformes & 2014 & Belgium & serology & 4 & $P C R$ & 10 \\
\hline Dickx et al., 2010 [44] & columbiformes & 2008 & Belgium & PCR \& culture & 4 & PCR \& culture & 19 \\
\hline \multirow[t]{2}{*}{ Dickx et al., 2010 [45] } & chickens & 2007 & Belgium & $\begin{array}{l}\text { PCR, culture \& } \\
\text { serology }\end{array}$ & 43 & PCR \& culture & 14 \\
\hline & turkeys & 2007 & Belgium & $\begin{array}{l}\text { PCR, culture \& } \\
\text { serology }\end{array}$ & 33 & PCR \& culture & 22 \\
\hline \multirow[t]{3}{*}{ Dickx et al., 2011 [46] } & chickens & 2010 & Belgium & PCR \& culture & $4^{b}$ & PCR \& culture & 19 \\
\hline & guinea fowl & 2010 & Belgium & PCR \& culture & $4^{b}$ & PCR \& culture & 19 \\
\hline & turkeys & 2010 & Belgium & PCR \& culture & $4^{b}$ & PCR \& culture & 19 \\
\hline Dovc et al., 2005 [47] & psittaciformes & 1997 & Slovenia & serology & 1 & serology & 3 \\
\hline Dovc et al., 2007 [48] & psittaciformes & unknown & Slovenia & serology & 1 & PCR \& serology & 6 \\
\hline
\end{tabular}


Table 1 Included studies describing human psittacosis cases and associated animal sources with strength of evidence score (Continued)

\begin{tabular}{|c|c|c|c|c|c|c|c|}
\hline Reference, year & Animal species & $\begin{array}{l}\text { Year of } \\
\text { notification }\end{array}$ & Country & Diagnostics human & $\begin{array}{l}\text { No. confirmed } \\
\text { human cases }\end{array}$ & $\begin{array}{l}\text { Diagnostics animal } \\
\text { and/or environment }\end{array}$ & $\begin{array}{l}\text { Strength of } \\
\text { evidence }\end{array}$ \\
\hline Elliot et al., 2001 [49] & unspecified birds & unknown & Australia & serology & 1 & no & 2 \\
\hline $\begin{array}{l}\text { Espinosa de los } \\
\text { Monteros et al., } 2005 \\
\text { [50] }\end{array}$ & psittaciformes & 2003 & Spain & PCR \& serology & 3 & PCR \& serology & 9 \\
\hline \multirow[t]{4}{*}{ Fenga et al., 2007 [25] } & cattle & 2005 & Italy & serology & $28^{b}$ & no & 8 \\
\hline & pigs & 2005 & Italy & serology & $28^{b}$ & no & 8 \\
\hline & goats & 2005 & Italy & serology & $28^{\mathrm{b}}$ & no & 8 \\
\hline & sheep & 2005 & Italy & serology & $28^{\mathrm{b}}$ & no & 8 \\
\hline $\begin{array}{l}\text { Ferreira et al., } 2015 \\
\text { [51] }\end{array}$ & psittaciformes & unknown & Brazil & serology & 3 & PCR & 8 \\
\hline $\begin{array}{l}\text { Ferreira et al., } 2017 \\
\text { [52] }\end{array}$ & psittaciformes & unknown & Brazil & serology & 1 & PCR & 6 \\
\hline Ferreri et al., 2007 [53] & passeriformes & 2000 & Italy & $\begin{array}{l}\text { PCR \& } \\
\text { immunohistochemistry }\end{array}$ & 1 & $\begin{array}{l}\text { PCR \& } \\
\text { immunohistochemistry }\end{array}$ & 17 \\
\hline \multirow[t]{3}{*}{ Fraeyman, $2010^{\mathrm{a}}[54]$} & columbiformes & unknown & Belgium & PCR \& serology & 1 & no & 3 \\
\hline & columbiformes & unknown & Belgium & PCR \& serology & 1 & no & 3 \\
\hline & columbiformes & unknown & Belgium & PCR \& serology & 1 & unknown & 3 \\
\hline \multirow[t]{4}{*}{ Frutos et al., 2012 [55] } & psittaciformes & 2010-2011 & Argentina & PCR & $6^{b}$ & no & 7 \\
\hline & chickens & 2010-2011 & Argentina & PCR & $1^{b}$ & no & 5 \\
\hline & columbiformes & 2010-2011 & Argentina & $P C R$ & $1^{b}$ & no & 5 \\
\hline & passeriformes & 2010-2011 & Argentina & PCR & $2^{b}$ & no & 5 \\
\hline \multirow{4}{*}{$\begin{array}{l}\text { Gacouin et al., } 2012 \\
\text { [56] }\end{array}$} & chickens & 1993-2011 & France & PCR or serology & $8^{b}$ & no & 3 \\
\hline & ducks & 1993-2011 & France & PCR or serology & $8^{b}$ & no & 3 \\
\hline & psittaciformes & 1993-2011 & France & PCR or serology & 2 & no & 1 \\
\hline & columbiformes & 1993-2011 & France & PCR or serology & 2 & no & 1 \\
\hline \multirow[t]{3}{*}{ Gaede et al., 2008 [8] } & chickens & 2005 & Germany & PCR \& serology & $7^{b}$ & PCR & 22 \\
\hline & ducks & 2005 & Germany & PCR \& serology & $7^{b}$ & PCR & 22 \\
\hline & geese & 2005 & Germany & PCR \& serology & $7^{b}$ & PCR & 22 \\
\hline $\begin{array}{l}\text { Garbim et al., } 2017 \\
\text { [57] }\end{array}$ & psittaciformes & unknown & Brazil & serology & 1 & no & 2 \\
\hline $\begin{array}{l}\text { García-Ordóñez et al., } \\
2011 \text { [58] }\end{array}$ & psittaciformes & 2009 & Spain & serology & 5 & PCR & 6 \\
\hline Geens et al., 2005 [59] & turkeys & unknown & Belgium & $P C R$ & 1 & PCR & 19 \\
\hline $\begin{array}{l}\text { Gelfand et al., } 2013 \\
\text { [60] }\end{array}$ & psittaciformes & unknown & $\begin{array}{l}\text { United States } \\
\text { of America }\end{array}$ & $\begin{array}{l}\text { serology \& } \\
\text { immunohistochemistry }\end{array}$ & 2 & $\begin{array}{l}\text { PCR \& } \\
\text { immunohistochemistry }\end{array}$ & 6 \\
\hline Haas et al., 2006 [9] & columbiformes & unknown & $\begin{array}{l}\text { The } \\
\text { Netherlands }\end{array}$ & serology & 1 & $P C R$ & 2 \\
\hline Haas et al., 2007 [61] & ducks & 2007 & Germany & $P C R$ & 1 & no & 5 \\
\hline $\begin{array}{l}\text { Harkinezhad et al., } \\
2007 \text { [62] }\end{array}$ & psittaciformes & unknown & Belgium & $\begin{array}{l}\text { PCR, culture \& } \\
\text { serology }\end{array}$ & 3 & PCR \& culture & 22 \\
\hline \multirow{4}{*}{$\begin{array}{l}\text { Harkinezhad et al., } \\
2009 \text { [63] }\end{array}$} & psittaciformes & $2002-2003$ & Belgium & PCR \& serology & 8 & no & 10 \\
\hline & columbiformes & $2002-2003$ & Belgium & PCR \& serology & 8 & no & 10 \\
\hline & passeriformes & $2002-2003$ & Belgium & PCR \& serology & 12 & no & 10 \\
\hline & turkeys & $2002-2003$ & Belgium & PCR \& serology & 1 & no & 4 \\
\hline $\begin{array}{l}\text { Heddema et al., } 2003 \\
\text { [64] }\end{array}$ & columbiformes & unknown & $\begin{array}{l}\text { The } \\
\text { Netherlands }\end{array}$ & PCR \& serology & 1 & PCR & 4 \\
\hline Heddema et al., 2006 & psittaciformes & 2005 & The & PCR \& serology & $10^{\mathrm{b}}$ & PCR & 20 \\
\hline
\end{tabular}


Table 1 Included studies describing human psittacosis cases and associated animal sources with strength of evidence score (Continued)

\begin{tabular}{|c|c|c|c|c|c|c|c|}
\hline Reference, year & Animal species & $\begin{array}{l}\text { Year of } \\
\text { notification }\end{array}$ & Country & Diagnostics human & $\begin{array}{l}\text { No. confirmed } \\
\text { human cases }\end{array}$ & $\begin{array}{l}\text { Diagnostics animal } \\
\text { and/or environment }\end{array}$ & $\begin{array}{l}\text { Strength of } \\
\text { evidence }\end{array}$ \\
\hline \multirow[t]{2}{*}{ [65] } & & & Netherlands & & & & \\
\hline & columbiformes & 2005 & $\begin{array}{l}\text { The } \\
\text { Netherlands }\end{array}$ & PCR \& serology & $10^{b}$ & PCR & 0 \\
\hline \multirow[t]{7}{*}{$\begin{array}{l}\text { Heddema et al., } 2015 \\
\text { [66] }\end{array}$} & psittaciformes & 2008-2013 & $\begin{array}{l}\text { The } \\
\text { Netherlands }\end{array}$ & PCR & $8^{b}$ & no & 7 \\
\hline & passeriformes & 2008-2013 & $\begin{array}{l}\text { The } \\
\text { Netherlands }\end{array}$ & PCR & $5^{b}$ & no & 7 \\
\hline & columbiformes & 2008-2013 & $\begin{array}{l}\text { The } \\
\text { Netherlands }\end{array}$ & PCR & $10^{\mathrm{b}}$ & no & 7 \\
\hline & ducks & 2008-2013 & $\begin{array}{l}\text { The } \\
\text { Netherlands }\end{array}$ & $P C R$ & $1^{b}$ & no & 5 \\
\hline & pheasants & 2008-2013 & $\begin{array}{l}\text { The } \\
\text { Netherlands }\end{array}$ & PCR & $1^{b}$ & no & 5 \\
\hline & $\begin{array}{l}\text { unspecified } \\
\text { poultry }\end{array}$ & 2008-2013 & $\begin{array}{l}\text { The } \\
\text { Netherlands }\end{array}$ & PCR & $5^{b}$ & no & 7 \\
\hline & unspecified birds & 2008-2013 & $\begin{array}{l}\text { The } \\
\text { Netherlands }\end{array}$ & PCR & $9^{b}$ & no & 7 \\
\hline $\begin{array}{l}\text { Henrion et al., } 2002 \\
\text { [67] }\end{array}$ & psittaciformes & 2001 & Belgium & serology & 1 & no & 2 \\
\hline \multirow[t]{5}{*}{ Hulin et al., 2015 [68] } & ducks & 2013 & France & PCR \& serology & 10 & PCR & 8 \\
\hline & chickens & 2013 & France & PCR \& serology & $7^{b}$ & PCR & 4 \\
\hline & turkeys & 2013 & France & PCR \& serology & $7^{b}$ & PCR & 4 \\
\hline & guinea fowl & 2013 & France & PCR \& serology & $7^{b}$ & PCR & 4 \\
\hline & $\begin{array}{l}\text { unspecified } \\
\text { poultry }\end{array}$ & 2013 & France & PCR \& serology & $7^{b}$ & PCR & 8 \\
\hline \multirow[t]{4}{*}{$\begin{array}{l}\text { lonescu et al., } 2016 \\
\text { [69] }\end{array}$} & psittaciformes & unknown & $\begin{array}{l}\text { United } \\
\text { Kingdom }\end{array}$ & PCR \& serology & $1^{b}$ & no & 6 \\
\hline & passeriformes & unknown & $\begin{array}{l}\text { United } \\
\text { Kingdom }\end{array}$ & PCR \& serology & $1^{b}$ & no & 6 \\
\hline & columbiformes & unknown & $\begin{array}{l}\text { United } \\
\text { Kingdom }\end{array}$ & PCR \& serology & $1^{b}$ & no & 6 \\
\hline & chickens & unknown & $\begin{array}{l}\text { United } \\
\text { Kingdom }\end{array}$ & PCR \& serology & $1^{b}$ & no & 6 \\
\hline Ito et al., 2002 [10] & psittaciformes & unknown & Japan & serology & 1 & no & 2 \\
\hline $\begin{array}{l}\text { Jiménez-Cordero } \\
\text { et al., } 2015 \text { [70] }\end{array}$ & columbiformes & unknown & Spain & serology & 1 & no & 2 \\
\hline Kaibu et al., 2006 [11] & psittaciformes & 2005 & Japan & PCR \& serology & 2 & PCR \& culture & 6 \\
\hline \multirow{3}{*}{$\begin{array}{l}\text { Kalmar et al., } 2014 \\
\text { [71] }\end{array}$} & columbiformes & unknown & Belgium & PCR \& culture & $3^{b}$ & PCR \& culture & 21 \\
\hline & passeriformes & unknown & Belgium & PCR \& culture & $3^{b}$ & PCR \& culture & 19 \\
\hline & strigiformes & unknown & Belgium & PCR \& culture & $3^{b}$ & PCR \& culture & 21 \\
\hline $\begin{array}{l}\text { Kampinga et al., } 2000 \\
\text { [72] }\end{array}$ & sheep & unknown & $\begin{array}{l}\text { The } \\
\text { Netherlands }\end{array}$ & PCR \& serology & 1 & no & 6 \\
\hline $\begin{array}{l}\text { Kovacova et al., } 2007 \\
\text { [12] }\end{array}$ & psittaciformes & 2005 & Slovakia & PCR \& serology & 1 & serology & 5 \\
\hline Lagae et al., 2014 [73] & chickens & 2012 & Belgium & PCR \& culture & 29 & PCR \& culture & 21 \\
\hline $\begin{array}{l}\text { Laroucau et al., } 2009 \\
\text { [74] }\end{array}$ & ducks & 2006 & France & PCR \& serology & 5 & PCR \& culture & 20 \\
\hline \multirow{2}{*}{$\begin{array}{l}\text { Laroucau et al., } 2015 \\
\text { [75] }\end{array}$} & chickens & 2013 & France & PCR \& serology & $5^{b}$ & PCR \& culture & 20 \\
\hline & ducks & 2013 & France & PCR \& serology & $5^{b}$ & $P C R$ & 20 \\
\hline
\end{tabular}


Table 1 Included studies describing human psittacosis cases and associated animal sources with strength of evidence score (Continued)

\begin{tabular}{|c|c|c|c|c|c|c|c|}
\hline Reference, year & Animal species & $\begin{array}{l}\text { Year of } \\
\text { notification }\end{array}$ & Country & Diagnostics human & $\begin{array}{l}\text { No. confirmed } \\
\text { human cases }\end{array}$ & $\begin{array}{l}\text { Diagnostics animal } \\
\text { and/or environment }\end{array}$ & $\begin{array}{l}\text { Strength of } \\
\text { evidence }\end{array}$ \\
\hline Ling et al., 2015 [76] & columbiformes & $2008-2010$ & China & $\begin{array}{l}\text { Antigen detection \& } \\
\text { serology }\end{array}$ & 19 & $\begin{array}{l}\text { Antigen detection \& } \\
\text { serology }\end{array}$ & 21 \\
\hline Lugert et al., 2017 [77] & ducks & 2010 & Germany & serology & 5 & no & 8 \\
\hline $\begin{array}{l}\text { Mair-Jenkins et al., } \\
2018 \text { [78] }\end{array}$ & columbiformes & 2015 & $\begin{array}{l}\text { United } \\
\text { Kingdom }\end{array}$ & PCR \& serology & 4 & no & 8 \\
\hline $\begin{array}{l}\text { Matsui et al., } 2008 \\
\text { [13] }\end{array}$ & unspecified birds & $2001-2002$ & Japan & serology & 8 & PCR & 12 \\
\hline Maza et al., 2016 [79] & psittaciformes & 2014 & Argentina & PCR & 2 & $\begin{array}{l}\text { PCR \& } \\
\text { immunohistochemistry }\end{array}$ & 5 \\
\hline \multirow{2}{*}{$\begin{array}{l}\text { Pandeli et al., } 2006 \\
\text { [80] }\end{array}$} & psittaciformes & unknown & Australia & PCR & $1^{\mathrm{b}}$ & no & 5 \\
\hline & fox & unknown & Australia & PCR & $1^{\mathrm{b}}$ & no & 5 \\
\hline \multirow[t]{2}{*}{$\begin{array}{l}\text { Petrovay et al., } 2008 \\
\text { [81] }\end{array}$} & $\begin{array}{l}\text { unspecified } \\
\text { poultry }\end{array}$ & 2005 & Hungary & PCR \& serology & 1 & no & 4 \\
\hline & $\begin{array}{l}\text { unspecified } \\
\text { poultry }\end{array}$ & 2007 & Hungary & PCR \& serology & 1 & no & 4 \\
\hline \multirow[t]{3}{*}{ Rehn et al., 2013 [82] } & unspecified birds & 2013 & Sweden & PCR & $15^{\mathrm{b}}$ & no & 11 \\
\hline & psittaciformes & 2013 & Sweden & PCR & $1^{b}$ & PCR & 5 \\
\hline & chickens & 2013 & Sweden & $P C R$ & $1^{\mathrm{b}}$ & PCR & 5 \\
\hline $\begin{array}{l}\text { Sciacca et al., } 2009 \\
\text { [83] }\end{array}$ & psittaciformes & 2009 & Belgium & serology & 1 & no & 2 \\
\hline Senn et al., 2008 [84] & psittaciformes & 2007 & Switzerland & serology & 1 & PCR & 4 \\
\hline \multirow[t]{3}{*}{$\begin{array}{l}\text { Speelberg et al., } 2014^{\mathrm{a}} \\
\text { [85] }\end{array}$} & musophagiformes & unknown & $\begin{array}{l}\text { The } \\
\text { Netherlands }\end{array}$ & PCR \& serology & 1 & no & 7 \\
\hline & columbiformes & unknown & $\begin{array}{l}\text { The } \\
\text { Netherlands }\end{array}$ & PCR \& serology & 1 & PCR & 7 \\
\hline & chickens & unknown & $\begin{array}{l}\text { The } \\
\text { Netherlands }\end{array}$ & PCR \& serology & 1 & $P C R$ & 5 \\
\hline \multirow[t]{6}{*}{$\begin{array}{l}\text { Spoorenberg et al., } \\
2016^{a} \text { [86] }\end{array}$} & unspecified birds & $2007-2010$ & $\begin{array}{l}\text { The } \\
\text { Netherlands }\end{array}$ & PCR \& serology & 1 & no & 8 \\
\hline & psittaciformes & $2007-2010$ & $\begin{array}{l}\text { The } \\
\text { Netherlands }\end{array}$ & PCR \& serology & 1 & no & 6 \\
\hline & unspecified birds & $2007-2010$ & $\begin{array}{l}\text { The } \\
\text { Netherlands }\end{array}$ & PCR \& serology & 1 & no & 4 \\
\hline & unspecified birds & $2007-2010$ & $\begin{array}{l}\text { The } \\
\text { Netherlands }\end{array}$ & PCR \& serology & 1 & no & 6 \\
\hline & columbiformes & $2007-2010$ & $\begin{array}{l}\text { The } \\
\text { Netherlands }\end{array}$ & PCR \& serology & 1 & no & 3 \\
\hline & unspecified birds & $2007-2010$ & $\begin{array}{l}\text { The } \\
\text { Netherlands }\end{array}$ & PCR \& serology & 1 & no & 3 \\
\hline $\begin{array}{l}\text { Sprague et al., } 2009 \\
\text { [87] }\end{array}$ & dogs & $2006-2007$ & Germany & culture \& serology & 2 & PCR \& culture & 10 \\
\hline Telfer et al., 2005 [15] & unspecified birds & 2002 & Australia & serology & 28 & no & 8 \\
\hline Tiong et al., 2007 [88] & ducks & 2003-2004 & Australia & serology & 12 & culture \& serology & 11 \\
\hline $\begin{array}{l}\text { Van Droogenbroeck } \\
\text { et al., } 2009 \text { [89] }\end{array}$ & turkeys & unknown & Belgium & PCR \& culture & 1 & PCR \& culture & 19 \\
\hline $\begin{array}{l}\text { Vande Weygaerde } \\
\text { et al., } 2018 \text { [16] }\end{array}$ & psittaciformes & unknown & Belgium & PCR \& serology & 1 & PCR & 17 \\
\hline $\begin{array}{l}\text { Vanrompay et al., } \\
2007 \text { [90] }\end{array}$ & psittaciformes & unknown & Belgium & PCR \& culture & 6 & PCR \& culture & 9 \\
\hline Verminnen et al., 2008 & turkeys & unknown & Belgium & PCR, culture \& & 3 & PCR, culture \& & 25 \\
\hline
\end{tabular}


Table 1 Included studies describing human psittacosis cases and associated animal sources with strength of evidence score (Continued)

\begin{tabular}{|c|c|c|c|c|c|c|c|}
\hline Reference, year & Animal species & $\begin{array}{l}\text { Year of } \\
\text { notification }\end{array}$ & Country & Diagnostics human & $\begin{array}{l}\text { No. confirmed } \\
\text { human cases }\end{array}$ & $\begin{array}{l}\text { Diagnostics animal } \\
\text { and/or environment }\end{array}$ & $\begin{array}{l}\text { Strength of } \\
\text { evidence }\end{array}$ \\
\hline [91] & & & & serology & & serology & \\
\hline $\begin{array}{l}\text { Vorimore et al., } 2015 \\
\text { [92] }\end{array}$ & ducks & 2009 & Belgium & serology & 4 & $P C R$ & 8 \\
\hline Walter et al., 2014 [93] & psittaciformes & unknown & $\begin{array}{l}\text { United } \\
\text { Kingdom }\end{array}$ & serology & 1 & no & 2 \\
\hline $\begin{array}{l}\text { Widgren et al., } 2009 \\
\text { [94] }\end{array}$ & psittaciformes & 2008 & Denmark & serology & 4 & unknown & 10 \\
\hline $\begin{array}{l}\text { Williams et al., } 2013 \\
\text { [95] }\end{array}$ & ducks & 2008 & $\begin{array}{l}\text { United } \\
\text { Kingdom }\end{array}$ & culture \& serology & 9 & no & 10 \\
\hline Yang et al., 2011 [96] & peacock & 2009 & China & PCR \& serology & 4 & PCR \& serology & 23 \\
\hline
\end{tabular}

${ }^{a}$ Studies reporting on multiple unrelated case studies

${ }^{b}$ Cases with multiple associated animal sources

for example occupationally exposed individuals or people living in areas with high animal or bird density $[25,28,29,34,44,45,63,68,73,76,77,88,90]$. Fifteen articles reported on outbreaks or prevalence of human psittacosis related to (mixed) poultry processing plants, farms or slaughterhouses (e.g. turkey, chicken and duck) $[8,28,30,45,46,68,73-75,77$, 88, 91, 92, 95, 96]. Other included articles described psittacosis cases in relation to a bird show or bird park [7, 13, 31], veterinary clinic or teaching hospital $[33,37,65,89]$, and a pet shop [10, 42, 50, 58, 94]. Psittaciformes were mentioned as animal source in 40 of the 136 (29\%) included associations, followed by columbiformes $(n=21,15 \%)$ and chickens $(n=15$, $11 \%)$. For eleven and four associations respectively, the bird or poultry species were not specified. Also mammalian species (e.g. horse, cattle, pig, goat, sheep, fox and dog) were considered as psittacosis source in eight instances. In 39 of the 136 (29\%) associations, there had been contact with a sick animal. In the large majority (58\%), however, contact with a sick animal was considered unknown. The characteristics and relevant extracted data of all included studies are listed in Additional file 1.

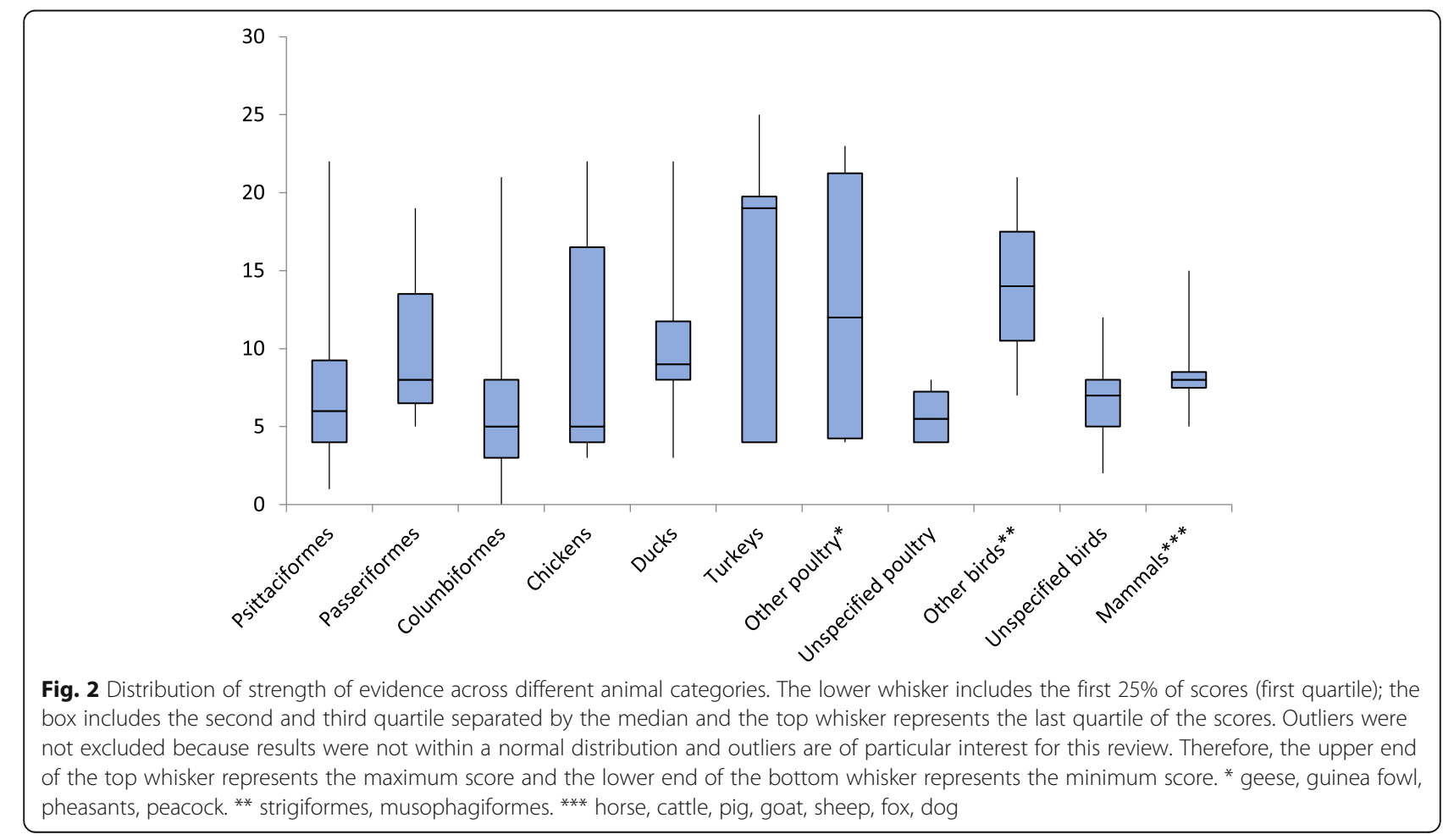




\section{Diagnostics in human and animal}

Most studies used polymerase-chain-reaction (PCR), serology or a combination of PCR and serology for human diagnostics (Table 1). In around half (71/136) of the human-animal associations, no diagnostics regarding animals and/or the environment were performed. When animal diagnostics were carried out, mostly PCR was used. In 55\% of the situations when PCR was applied for human diagnostics, genotyping of the C. psittaci strain was also performed.

\section{Strength of evidence across animal categories}

Figure 2 presents the distribution of strength of evidence for zoonotic transmission by animal category in boxplots. High maximum scores for strength of evidence were obtained for turkeys (25), chickens (22), ducks (22), psittaciformes (22), columbiformes (21) and passeriformes (19). The category 'other poultry', including geese, guinea fowl, pheasant and peacock, had also a high maximum score of 23. 'Unspecified poultry' and 'unspecified birds' only had a maximum score of 8 and 12 respectively. Median scores for strength of evidence were highest for turkeys (19). The single description of zoonotic transmission from strigiformes and peacock had a relatively high strength of evidence score of 21 and 23 respectively [71, 96]. For both geese and guinea fowls, two descriptions of animal-human transmission were found, with one description scoring low (4) $[38,68]$ and the other scoring high (geese (22) [8], guinea fowl (19) [46]). The single association with dogs had a score of 10 and two single reports from a fox and pheasant scored relatively low with 5 points each $[66,80$, 87]. In the scoring system used in this article, the factor 'genotypical match' was given the highest weight (i.e. 8 points). Additional file 2 provides an interactive version of the strength of evidence tool, allowing the reader to replace the default scores by user-defined scores. A genotypical match between the human and animal or environmental samples was found for the animal categories chicken, columbiformes, ducks, geese, guinea fowl, passeriformes, peacock, psittaciformes, strigiformes and turkeys (Table 2). Ferreri et al. concluded that patient and animal were infected by the same C. psittaci strain, however, the genotype was not specified [53]. The association with columbiformes from Heddema et al. (2006) had an strength of evidence of zero, because of a genotypical mismatch between the human and animal samples [65].

\section{Discussion}

This review shows that, in addition to the traditionally reported parrot-like birds and to lesser extent pigeons, there is evidence for zoonotic transmission of $C$. psittaci from turkeys, chickens and ducks. In fact, based on our selfdeveloped scoring system, the evidence was generally stronger for turkey and other poultry than for parrot-like birds. Moreover, zoonotic transmission from owls, peacock, geese and even mammals was reported.

Psittaciformes still remain an important source of human psittacosis, as almost one-third of the included zoonotic associations included in this review reported on psittaciformes, however, the overall strength of evidence was low. A possible explanation for our finding that the evidence for psittaciformes is relatively weak could be that clinicians and public health officials consider contact of a pneumonia patient with a parrot-like bird as sufficient evidence for psittacosis and for starting presumptive antibiotic treatment. The fact that psittacine birds are generally accepted as source of $C$. psittaci also introduces publication bias, as systematic research is performed to a lesser extent. However, when several human cases are involved and a thorough source trace-back investigation is performed, evidence for zoonotic transmission from psittaciformes can be very strong $[42,65]$.

In contrast, physicians might disregard turkeys and other poultry species as a source for zoonotic transmission of C. psittaci. 'Natural immunity', due to continuous exposure, has been suggested for individuals who are regularly in close contact with poultry, because in some studies most of the C. psittaci culture- and PCR-positive poultry workers did not present with any clinical signs [45, 46]. Contrastingly, Lagae et al. found that 25 out of 29 C. psittaci PCR-positive poultry farmers reported symptoms possibly related to psittacosis [73]. Since genotypes A, C and D found by Dickx et al. [46] were identical to those described by Lagae et al. [73], it is less likely that the difference between symptomatic and asymptomatic infections can be attributed to a difference in genotype. The diverging findings show that more research into asymptomatic infection and natural immunity of human psittacosis related to poultry is required.

A genotypical match between human and animal samples has been documented for chickens, columbiformes, ducks, geese, guinea fowl, passeriformes, peacock, psittaciformes, strigiformes and turkeys. Host specificity of genotypes has been described, with genotype A being mostly linked to psittacine birds, $\mathrm{B}$ and $\mathrm{E}$ to pigeons, $\mathrm{D}$ and $E$ to turkeys, and $C$ and $E / B$ to ducks $[1,75]$. Generally, these patterns of host specificity are also found in the genotypical matches summarized in this review, but exceptions are present. In turkeys, for example, genotypical matches were very divergent, as matches were also reported for the genotypes $\mathrm{A}, \mathrm{C}$ and $\mathrm{E} / \mathrm{B}$, which are generally more specific for psittacine birds and ducks. Detection of a specific genotype in a human psittacosis case can give a direction for the possible animal source. However, during source tracing, also the non-genotypehost specific animal sources need to be kept in mind. Furthermore, this 'macro' level of genotype matching to 
Table 2 Overview of studies demonstrating a genotypical match between human and animal or environmental samples

\begin{tabular}{|c|c|c|c|c|}
\hline Animal category & Reference & Genotype human & Genotype animal & Genotype environment \\
\hline \multirow[t]{4}{*}{ Chickens } & Dickx et al., 2011 [46] & $A, C \& D$ & - & $\mathrm{D}$ \\
\hline & Gaede et al., 2008 [8] & A & $A \& E / B$ & - \\
\hline & Lagae et al., 2014 [73] & $A, C \& D$ & $A \& D$ & - \\
\hline & Laroucau et al., 2015 [75] & $E / B$ & $E / B$ & - \\
\hline \multirow[t]{4}{*}{ Columbiformes } & Arraiz et al., 2012 [29] & B & B & - \\
\hline & Dickx et al., 2010 [44] & D & - & D \\
\hline & Kalmar et al., 2014 [71] & B & B & - \\
\hline & Ling et al., 2015 [76] & B & B & - \\
\hline \multirow[t]{3}{*}{ Ducks } & Gaede et al., 2008 [8] & A & $A \& E / B$ & - \\
\hline & Laroucau et al., 2009 [74] & $E / B$ & $E / B$ & - \\
\hline & Laroucau et al., 2015 [75] & $E / B$ & $E / B$ & - \\
\hline Geese & Gaede et al., 2008 [8] & A & $A \& E / B$ & - \\
\hline Guinea fowl & Dickx et al., 2011 [46] & $A, C \& D$ & - & $A \& C$ \\
\hline \multirow[t]{2}{*}{ Passeriformes } & Ferreri et al., 2007 [53] & unknown & unknown & - \\
\hline & Kalmar et al., 2014 [71] & B & $A \& B$ & - \\
\hline Peacock & Yang et al., 2011 [96] & B & B & - \\
\hline \multirow[t]{6}{*}{ Psittaciformes } & Cadario et al., 2017 [35] & A & A & - \\
\hline & Cadario et al., 2017 [35] & A & A & - \\
\hline & De Boeck et al., 2016 [42] & A & - & A \\
\hline & Harkinezhad et al., 2007 [62] & $E / B$ & $E / B$ & - \\
\hline & Heddema et al., 2006 [65] & A & A & - \\
\hline & Vande Weygaerde et al., 2018 [16] & A & A & - \\
\hline Strigiformes & Kalmar et al., 2014 [71] & B & B & - \\
\hline \multirow[t]{5}{*}{ Turkeys } & Dickx et al., 2010 [45] & D & D & - \\
\hline & Dickx et al., 2011 [46] & $A, C \& D$ & - & $A \& C$ \\
\hline & Geens et al., 2005 [59] & $D, F \& E / B$ & $D, F \& E / B$ & - \\
\hline & Van Droogenbroeck et al., 2009 [89] & $D, E \& E / B$ & $D, E \& E / B$ & - \\
\hline & Verminnen et al., 2008 [91] & A & A & - \\
\hline
\end{tabular}

confirm animal-human transmission has its limitations, as strain identity is less accurately defined compared to whole genome sequencing.

Results from this review also indicate the possibility of mammals being a source of $C$. psittaci infection to humans, but the strength of evidence for zoonotic transmission for these mammalian species was relatively low. The outbreak of three psittacosis cases in a veterinary school linked to exposure to infected fetal membranes of a mare did have a maximum score of 15 [37]. This could indicate a novel source of infection, but genotyping was only performed on the animal sample.

There are several reports of occurrence of C. psittaci in mammalian species [97-102]. However, this occurrence is often attributed to transmission from birds to mammals $[100,101,103]$. This was also suggested in the article describing zoonotic transmission from a mare, as it seemed feasible that the mare contracted the bacterium from wild birds in the surrounding area. This might indicate that mammalian species are not the reservoir of the disease, but act as an intermediate species in the transmission to humans. Nevertheless, it is important to further investigate transmission dynamics of $C$. psittaci within and between animal populations, as animal-to-animal transmission of a bovine isolate of $C$. psittaci in calves has been reported [104]. The possibility of zoonotic transmission from nonavian animals should be further investigated. Moreover, there has been evidence for human-to-human transmission of $C$. psittaci [10, 105, 106].

Recently, a C. psittaci related species named C. gallinaceae has been added to the family of Chlamydiaceae [107], with chickens and turkeys as the predominant hosts. Hulin et al. investigated the presence of $C$. psittaci as well as C. gallinaceae in poultry. They found a high prevalence of $C$. gallinaceae in a slaughterhouse where chickens, guinea fowls and turkeys were processed [68]. 
Human cases related to other species than C. psittaci were not included in this review, however, the high prevalence of $C$. gallinaceae in poultry indicates the need to assess the zoonotic potential of this relatively unknown species.

This review has some limitations. Although we included multiple languages in our search strategy, the geographical spread of articles included in our review is limited, as the majority of studies is from the European region. A relatively large number of studies originated from Belgium, the Netherlands and France, and these predominantly investigated poultry. This may reflect a particular interest in psittacosis related to poultry among researchers from these countries. Partly, this could be due to the fact that psittacosis in poultry is a notifiable disease in Belgium [108], however, not in the Netherlands and France.

We did not qualitatively review the study design of the included articles, as the majority of the included articles were case studies. This type of study design is considered of low quality and reliability. Data extraction was also difficult, as the description of human cases and animal sources was relatively poor in some studies. However, we did always extract the data according the original authors rationale.

In fifteen studies, human cases were described with multiple associated animal sources. The aim of this review was to give an overview of all associated animal sources. Therefore, in case of multiple exposures, the animal sources were entered into separate lines under the same study, which causes human cases to be entered twice. Moreover, when multiple animals are associated, it could be that for some animal species the suspicion of being the actual source of infection is low, but are included in the investigation for certainty, which can cause bias towards a lower evidence score for these animal sources.

The strength of evidence score is based on a selfdeveloped scoring system, in which a weight was assigned to each factor included in the calculation. The subjectivity of the weights influences the strength of evidence score. With a weight of 8 , the factor 'genotypical match' had a high impact on the final strength of evidence scores. As the genotype matching was made on a 'macro' level, a score of 8 is disputable. When assigning a weight of 4 to this factor, as means of a sensitivity analysis, the boxplot summary scores are lower, but the general pattern and conclusion between animal categories remain stable. For transparency, all the raw data and a flexible strength of evidence calculation tool have been included in Additional file 2 . This allows the reader to manually adjust the weights and interpret the effects on the individual strength of evidence scores, as well as on the boxplot summary scores for the different animal categories.

The included studies showed a wide variety in tests used to confirm a case, e.g. PCR, serology, culture or combinations. Even between studies, that reported to use PCR, discrepancies were present, as the applied PCR methods varied in amplification techniques, specificity and DNA targets. Also the type of serological test applied (e.g. Enzyme-Linked Immunosorbent Assay, immunofluorescence, complement fixation test) differed. Apart from antigen and/or antibody testing, the specific type of test and the corresponding sensitivity or specificity values of these tests were not taken into account in our review, meaning that the reliability of the number of confirmed individuals varies per study included. We maintained the number of cases as stated in the original article, because some articles did not mention a case definition, and other articles differed too much in sampling methods and type of test to distinguish between case definitions. This broad range of tests and criteria for case confirmations is in line with the main findings of a review by Nieuwenhuizen et al. on laboratory methods for case finding in human psittacosis outbreaks [14]. They concluded that there is no standard or uniformity in tests used to confirm human cases. In general, exposure assessment in most studies was rather weak, mostly lacking specification of the chronology of events. We therefore reported 'contact with sick animals' irrespective of when exactly the animals became ill. People can also become infected after contact with asymptomatic animals [109], but sick animals are likely to shed more bacteria, thus having a higher chance of transmission, which is why contact with sick animals was assigned a higher weight. However, asymptomatic animals may pose a higher threat to public health because they are less evident as a source and may cause more delay in diagnosing the disease in humans.

\section{Conclusion}

Based on our scoring system, strong evidence was found for zoonotic transmission from turkeys, chickens and ducks. The evidence was generally stronger for poultry than for parrot-like birds. One explanation could be that contact of a pneumonia patient with a parrot-like bird is often regarded as sufficient evidence, while thorough source investigation is only performed when nontraditionally reported species are implicated. Despite their low strength of evidence, psittaciformes and pigeons remain important sources of zoonotic transmission of C. psittaci, as is reflected by the large proportion of included studies reporting on psittaciformes and pigeons. In addition to the traditionally reported species, clinicians and public health officials should consider turkey, chicken, duck and other bird species (e.g. musophagiformes and strigiformes) as potential sources of human psittacosis cases and include these species in medical history and source tracing. 


\section{Supplementary information}

Supplementary information accompanies this paper at https://doi.org/10. 1186/s12879-020-4918-y

Additional file 1. Characteristics of 80 included studies.

Additional file 2. Strength of evidence tool.

\section{Abbreviations}

C. psittaci: Chlamydia psittaci; CAP: Community acquired pneumonia;

PCR: Polymerase chain reaction

\section{Acknowledgements}

We would like to thank Annelies Nieuwenhuizen for her useful comments and suggestions on the manuscript as well as Wim ten Have, information specialist at RIVM, for his assistance with the literature search and search strategies.

\section{Authors' contributions}

WvdH and LH conceived the study. LH, IR, MdJ and WvdH made substantial contribitions to the design of this review. IR, MdJ, LH, WvdH and FD contributed to the acquisition, analysis and interpretation of data. All authors read and approved the final manuscript.

\section{Funding}

This study was funded from the regular budget of the National Institute for Public Health and the Environment (project number V/150207) and from the Plat4m-2Bt-psittacosis project (https://www.wur.nl/nl/show/Plat4m2Btpsittacose.htm), granted by ZonMw, the Netherlands organization for Health Research and Development (project number 522001002).

The funders had no role in study design, data collection, data analysis, decision to publish, or preparation of the manuscript.

\section{Availability of data and materials}

All data generated or analysed during this study are included in this published article and/or its supplementary information files.

\section{Ethics approval and consent to participate}

Not applicable.

\section{Consent for publication}

Not applicable.

\section{Competing interests}

The authors declare that they have no competing interests.

\section{Author details}

${ }^{1}$ Centre for Infectious Disease Control, National Institute for Public Health and the Environment, Bilthoven, the Netherlands. ${ }^{2}$ Faculty of Veterinary Medicine, Utrecht University, Utrecht, the Netherlands.

Received: 21 December 2018 Accepted: 26 February 2020 Published online: 04 March 2020

\section{References}

1. Andersen AA, Vanrompay D. Avian chlamydiosis. Rev Sci Tech. 2000;19(2): 396-404.

2. Smith KA, Campbell CT, Murphy J, Stobierski MG, Tengelsen LA Compendium of measures to control Chlamydophila psittaci infection among humans (psittacosis) and pet birds (avian chlamydiosis), 2010 National Association of State Public Health Veterinarians (NASPHV). J Exot Pet Med. 2011:20(1):32-45.

3. Elkeles G, Barros E. Die Psittacosis (Papageienkrankheit) mit besondere Berücksichtigung der Pandemie des Jahres 1929/30. In: Weichardt W, editor. Ergebnisse der Hygiene Bakteriologie Immunitätsforschung und Experimentellen Therapie. Berlin, Heidelberg: Springer; 1931

4. Meyer KF, Eddie B, Stevens IM. Recent studies on psittacosis. Am J Public Health Nations Health. 1935;25(5):571-9.

5. Ramsay EC. The psittacosis outbreak of 1929-1930. J Avian Med Surg. 2003;17(4):235-7.
6. Newman CP, Palmer SR, Kirby FD, Caul EO. A prolonged outbreak of ornithosis in duck processors. Epidemiol Infect. 1992;108(1):203-10.

7. Berk Y, Klaassen CHW, Mouton JW, Meis JFGM. An outbreak of psittacosis in a bird-fanciers fair in the Netherlands (Een uitbraak van psittacose na een vogelbeurs). Nederlands Tijdschrift voor Geneeskunde. 2008;152(34):1889-92.

8. Gaede W, Reckling KF, Dresenkamp B, Kenklies S, Schubert E, Noack U, et al. Chlamydophila psittaci infections in humans during an outbreak of psittacosis from poultry in Germany. Zoonoses Public Health. 2008;55(4): $184-8$

9. Haas LE, Tjan DH, Schouten MA, van Zanten AR. Severe pneumonia from psittacosis in a bird-keeper. Ned Tijdschr Geneeskd. 2006;150(3):117-21.

10. Ito I, Ishida T, Mishima M, Osawa M, Arita M, Hashimoto T, et al. Familial cases of psittacosis: possible person-to-person transmission. Intern Med. 2002:41(7):580-3.

11. Kaibu H, lida $K$, Ueki $S$, Ehara $H$, Shimasaki $Y$, Watanabe $S$, et al. Psittacosis in all four members of a family in Nagasaki, Japan. Jpn J Infect Dis. 2006;59(5): 349-50.

12. Kovacova E, Majtan J, Botek R, Bokor T, Blaskovicova H, Solavova M, et al. A fatal case of psittacosis in Slovakia, January 2006. Euro Surveill. 2007;12(8): E070802.1.

13. Matsui T, Nakashima K, Ohyama T, Kobayashi J, Arima Y, Kishimoto T, et al An outbreak of psittacosis in a bird park in Japan. Epidemiol Infect. 2008; 136(4):492-5.

14. Nieuwenhuizen AA, Dijkstra F, Notermans DW, van der Hoek W. Laboratory methods for case finding in human psittacosis outbreaks: a systematic review. BMC Infect Dis. 2018;18(1):442.

15. Telfer BL, Moberley SA, Hort KP, Branley JM, Dwyer DE, Muscatello DJ, et al. Probable psittacosis outbreak linked to wild birds. Emerg Infect Dis. 2005; 11(3):391-7.

16. Vande Weygaerde $Y$, Versteele C, Thijs E, De Spiegeleer A, Boelens J Vanrompay D, et al. An unusual presentation of a case of human psittacosis. Respir Med Case Rep. 2018;23:138-42.

17. Arenas-Valls N, Chacon S, Perez A, Del Pozo R. Atypical Chlamydia psittaci pneumonia. Four related cases. Arch Bronconeumol. 2017:53(5):277-9.

18. Yung AP, Grayson ML. Psittacosis--a review of 135 cases. Med J Aust. 1988; 148(5):228-33.

19. Crosse BA. Psittacosis: a clinical review. J Infect. 1990;21(3):251-9.

20. de Gier B, Hogerwerf L, Dijkstra F, van der Hoek W. Disease burden of psittacosis in the Netherlands. Epidemiol Infect. 2018;146(3):303-5.

21. Hogerwerf L, De Gier B, Baan B, Van Der Hoek W. Chlamydia psittaci (psittacosis) as a cause of community-acquired pneumonia: a systematic review and meta-analysis. Epidemiol Infect. 2017;145(15):3096-105.

22. Van der Hoek W, Van Gageldonk-Lafeber AB, Heddema ER, Notermans DW, den Boer JW, Nieuwenhuizen A, et al. Omvang van het psittacose-probleem bij de mens: het belang van betrouwbare diagnostiek. Infectieziekten Bull. 2014;25(2):45-8.

23. Deschuyffeleer TP, Tyberghien LF, Dickx VL, Geens T, Saelen JM, Vanrompay DC, et al. Risk assessment and management of Chlamydia psittaci in poultry processing plants. Ann Occup Hyg. 2012:56(3):340-9.

24. Haag-Wackernagel $\mathrm{D}$, Moch $\mathrm{H}$. Health hazards posed by feral pigeons. $J$ Infect. 2004:48(4):307-13

25. Fenga C, Cacciola A, Di Nola C, Calimeri S, Lo Giudice D, Pugliese M, et al. Serologic investigation of the prevalence of Chlamydophila psittaci in occupationally-exposed subjects in eastern Sicily. Ann Agric Environ Med. 2007;14(1):93-6.

26. Verminnen K, Vanrompay D. Chlamydophila psittaci infections in turkeys: overview of economic and zoonotic importance and vaccine development. Drugs Today (Barc). 2009;45(Suppl B):147-50.

27. Everett KD, Bush RM, Andersen AA. Emended description of the order Chlamydiales, proposal of Parachlamydiaceae fam. nov. and Simkaniaceae fam. nov., each containing one monotypic genus, revised taxonomy of the family Chlamydiaceae, including a new genus and five new species, and standards for the identification of organisms. Int J Syst Bacteriol. 1999;49(Pt 2):415-40.

28. Abadia G, Capek I, André-Fontaine G, Laurens E. Study of the seroprevalence of avian chlamydiosis in certain poultry workers in Brittany and Pays de la Loire, 2001-2002: Les zoonoses en France. Bull Épidémiol Hebd. 2006;2006(27/28):204-5.

29. Arraiz N, Bermudez V, Urdaneta B, Mujica E, Sanchez MP, Mejia R, et al. Evidence of zoonotic Chlamydophila psittaci transmission in a population at risk in Zulia state, Venezuela. Rev Salud Publica (Bogota). 2012;14(2):305-14. 
30. Belchior E, Bradane G, Mercier AF, Fortin N, Ollivier R, Hubert B. Investigations of human cases of psittacosis in two poultry plants, Pays de la Loire, March-April 2009. Épidémiologie et Santé Animale. 2010(57):5-11.

31. Belchior E, Barataud D, Ollivier R, Capek I, Laroucau K, de Barbeyrac B, et al. Psittacosis outbreak after participation in a bird fair, Western France, December 2008. Epidemiol Infect. 2011;139(10):1637-41.

32. Bourne D, Beck N, Summerton CB. Chlamydia psittaci pneumonia presenting as acute generalised peritonism. Emerg Med J. 2003:20(4):386-7.

33. Branley JM, Roy B, Dwyer DE, Sorrell TC. Real-time PCR detection and quantitation of Chlamydophila psittaci in human and avian specimens from a veterinary clinic cluster. Eur J Clin Microbiol Infect Dis. 2008;27(4):269-73.

34. Branley JM, Weston KM, England J, Dwyer DE, Sorrell TC. Clinical features of endemic community-acquired psittacosis. New Microbes New Infect. 2014;2(1):7-12

35. Cadario ME, Frutos MC, Arias MB, Origlia JA, Zelaya V, Madariaga MJ, et al. Epidemiological and molecular characteristics of Chlamydia psittaci from 8 human cases of psittacosis and 4 related birds in Argentina. Rev Argent Microbiol. 2017;49(4):323-7

36. Carlier L, Kempf M, Aaziz R, Jolivet-Gougeon A, Laroucau K. A severe case of pneumopathy in a duck breeder due to Chlamydia psittaci diagnosed by 16S rDNA sequencing. JMM Case Rep. 2014;1(3):e001537.

37. Chan J, Doyle B, Branley J, Sheppeard V, Gabor M, Viney K, et al. An outbreak of psittacosis at a veterinary school demonstrating a novel source of infection. One Health. 2017;3:29-33.

38. Chau S, Tso EY, Leung WS, Fung KS. Three cases of atypical pneumonia caused by Chlamydophila psittaci. Hong Kong Med J. 2015;21(3):272-5.

39. Cheng YJ, Lin KY, Chen CC, Huang YL, Liu CE, Li SY. Zoonotic atypical pneumonia due to Chlamydophila psittaci: first reported psittacosis case in Taiwan. J Formos Med Assoc. 2013;112(7):430-3

40. Ciftci B, Guler ZM, Aydogdu M, Konur O, Erdogan Y. Familial outbreak of psittacosis as the first Chlamydia psittaci infection reported from Turkey. Tuberk Toraks. 2008;56(2):215-20.

41. Clarence D, Patel J, Sunny S. Atypical pneumonia - a case where a newer test improved outcome. J Intensive Care Soc. 2016;17(4):100-1.

42. De Boeck C, Dehollogne C, Dumont A, Spierenburg M, Heijne M, Gyssens I, et al. Managing a cluster outbreak of psittacosis in Belgium linked to a pet shop visit in the Netherlands. Epidemiol Infect. 2016;144(8):1710-6.

43. De Schrijver $\mathrm{K}$, Vercammen $\mathrm{F}$, Alen $\mathrm{Y}$. Psittacosis in animal caretakers in a zoo. Tijdschrift voor Bedrijfs- en Verzekeringsgeneeskunde. 2016;24(1):28-31.

44. Dickx V, Beeckman DS, Dossche L, Tavernier P, Vanrompay D. Chlamydophila psittaci in homing and feral pigeons and zoonotic transmission. J Med Microbiol. 2010;59(Pt 11):1348-53.

45. Dickx V, Geens T, Deschuyffeleer T, Tyberghien L, Harkinezhad T, Beeckman DS, et al. Chlamydophila psittaci zoonotic risk assessment in a chicken and turkey slaughterhouse. J Clin Microbiol. 2010;48(9):3244-50.

46. Dickx V, Vanrompay D. Zoonotic transmission of Chlamydia psittaci in a chicken and turkey hatchery. J Med Microbiol. 2011;60(Pt 6):775-9.

47. Dovc A, Dovc P, Kese D, Vlahovic K, Pavlak M, Zorman-Rojs O. Long-term study of Chlamydophilosis in Slovenia. Vet Res Commun. 2005;29(Suppl 1):23-36.

48. Dovč A, Slavec B, Lindtner-Knific R, Zorman-Rojs O, Račnik J, Golja J, et al. Study of Chlamydophila psittaci outbreak in budgerigars. Bull Vet Inst Pulawy. 2007;51(3):343-6.

49. Elliott JH. Psittacosis. A flu like syndrome. Aust Fam Physician. 2001;30(8):739-41.

50. Espinosa de los Monteros MT, Laguna Sorina JA, Rueda da Domingo MT, Lopez Hernandez B, Bermejo Perez MJ, Sabonet JC. Psittacosis outbreak in Granada, Spain. Rev Esp Salud Publica. 2005;79(5):591-7.

51. Ferreira $\mathrm{VL}$, et al. Psittacosis associated with pet bird ownership: a concern for public health. JMM Case Reports. 2015;2:1-5. https://doi.org/10.1099/ jmmcr.0.000085

52. Ferreira VL, Silva MV, Bassetti BR, Pellini ACG, Raso TF. Intersectoral action for health: preventing psittacosis spread after one reported case. Epidemiol Infect. 2017;145(11):2263-8

53. Ferreri AJ, Dolcetti R, Magnino S, Doglioni C, Cangi MG, Pecciarini L, et al. A woman and her canary: a tale of chlamydiae and lymphomas. J Natl Cancer Inst. 2007;99(18):1418-9.

54. Fraeyman A, Boel A, Van Vaerenbergh K, De Beenhouwer H. Atypical pneumonia due to Chlamydophila psittaci: 3 case reports and review of literature. Acta Clin Belg. 2010;65(3):192-6.

55. Frutos MC, Monetti M, Kiguen X, Venezuela F, Re V, Cuffini C. Genotyping of C. psittaci in central area of Argentina. Diagn Microbiol Infect Dis. 2012;74(3):320-2.
56. Gacouin A, Revest M, Letheulle J, Fillatre P, Jouneau S, Piau C, et al. Distinctive features between community-acquired pneumonia (CAP) due to Chlamydophila psittaci and CAP due to Legionella pneumophila admitted to the intensive care unit (ICU). Eur J Clin Microbiol Infect Dis. 2012;31(10): 2713-8.

57. Garbim BB, SZP R, Quadros K, Belangero VMS, Oliveira RB. Hypercalcemia in children: three cases report with unusual clinical presentations. J Bras Nefrol. 2017;39(2):213-6.

58. Garcia-Ordonez MA, Blanco-Gonzalez JI, Villanueva-Agero R, Pozo-Munoz F. Psitacosis outbreak in the northern region of Malaga, Spain. Aten Primaria. 2012:44(2):e11-2.

59. Geens T, Dewitte A, Boon N, Vanrompay D. Development of a Chlamydophila psittaci species-specific and genotype-specific real-time PCR. Vet Res. 2005;36(5-6):787-97.

60. Gelfand MS, Cleveland KO. Family outbreak of psittacosis with an exhumation-based diagnosis: following in the footsteps of Dr. House Am J Med Sci. 2013;345(3):252-3

61. Haas WH, Swaan CM, Meijer A, Neve G, Buchholz U, Beer M, et al. A Dutch case of atypical pneumonia after culling of $\mathrm{H} 5 \mathrm{~N} 1$ positive ducks in Bavaria was found infected with Chlamydophila psittaci. Euro Surveill. 2007;12(11): E071129.3.

62. Harkinezhad T, Verminnen K, Van Droogenbroeck C, Vanrompay D. Chlamydophila psittaci genotype E/B transmission from African grey parrots to humans. J Med Microbiol. 2007;56(Pt 8):1097-100.

63. Harkinezhad T, Verminnen K, De Buyzere M, Rietzschel E, Bekaert S, Vanrompay D. Prevalence of Chlamydophila psittaci infections in a human population in contact with domestic and companion birds. J Med Microbiol. 2009:58(Pt 9):1207-12.

64. Heddema ER, Kraan MC, Buys-Bergen HE, Smith HE, Wertheim-van Dillen PM. A woman with a lobar infiltrate due to psittacosis detected by polymerase chain reaction. Scand J Infect Dis. 2003;35(6-7):422-4.

65. Heddema ER, van Hannen EJ, Duim B, de Jongh BM, Kaan JA, van Kessel R, et al. An outbreak of psittacosis due to Chlamydophila psittaci genotype A in a veterinary teaching hospital. J Med Microbiol. 2006:55(Pt 11):1571-5.

66. Heddema ER, van Hannen EJ, Bongaerts M, Dijkstra F, Ten Hove RJ, de Wever B, et al. Typing of Chlamydia psittaci to monitor epidemiology of psittacosis and aid disease control in the Netherlands, 2008 to 2013. Euro Surveill. 2015;20(5):21026.

67. Henrion E, Trippaerts M, Lepage P. Severe psittacosis with multiorgan failure in a 10 year-old boy (Psittacose sévère multiviscérale chez un garçon de dix ans). Arch Pediatr. 2002;9(8):810-3.

68. Hulin V, Oger S, Vorimore F, Aaziz R, de Barbeyrac B, Berruchon J, et al. Host preference and zoonotic potential of Chlamydia psittaci and C. gallinacea in poultry. Pathog Dis. 2015;73(1):1-11.

69. Ionescu A-M, Khare D, Kavi J. Birds of a feather: an uncommon cause of pneumonia and meningoencephalitis. BMJ Case Reports. 2016;2016: bcr2016216879.

70. Jimenez-Cordero J, Jimenez-Pernudo O. Headache, fever and myalgia: atypical pneumonia caused by Chlamydia psittaci. Semergen. 2016:42(5):338-40.

71. Kalmar ID, Dicxk V, Dossche L, Vanrompay D. Zoonotic infection with Chlamydia psittaci at an avian refuge centre. Vet J. 2014;199(2):300-2

72. Kampinga GA, Schroder FP, Visser IJ, Anderson JM, Buxton D, Moller AV. Lambing ewes as a source of severe psittacosis in a pregnant woman. Ned Tijdschr Geneeskd. 2000;144(52):2500-4.

73. Lagae S, Kalmar I, Laroucau K, Vorimore F, Vanrompay D. Emerging Chlamydia psittaci infections in chickens and examination of transmission to humans. J Med Microbiol. 2014;63(Pt 3):399-407.

74. Laroucau K, de Barbeyrac B, Vorimore F, Clerc M, Bertin C, Harkinezhad T, et al. Chlamydial infections in duck farms associated with human cases of psittacosis in France. Vet Microbiol. 2009;135(1-2):82-9.

75. Laroucau K, Aaziz R, Meurice L, Servas V, Chossat I, Royer H, et al. Outbreak of psittacosis in a group of women exposed to Chlamydia psittaci-infected chickens. Euro Surveill. 2015;20(24).

76. Ling Y, Chen H, Chen X, Yang X, Yang J, Bavoil PM, et al. Epidemiology of Chlamydia psittaci infection in racing pigeons and pigeon fanciers in Beijing, China. Zoonoses Public Health. 2015;62(5):401-6.

77. Lugert R, Gross U, Masanta WO, Linsel G, Heutelbeck A, Zautner AE. Seroprevalence of Chlamydophila psittaci among employees of two German duck farms. Eur J Microbiol Immunol (Bp). 2017;7(4):267-73.

78. Mair-Jenkins J, Lamming T, Dziadosz A, et al. A Psittacosis Outbreak among English Office Workers with Little or No Contact with Birds, August 2015. 
Plos Curr. 2018;10. https://doi.org/10.1371/currents.outbreaks. b646c3bb2b4f0e3397183f31823bbca6.

79. Maza Y, Chaparro M, Argañaráz C, Genero S. Psittacosis outbreak in Fontana (Chaco, Argentina) during january 2014. Rev Vet. 2016;27(1):45-7.

80. Pandeli V, Ernest D. A case of fulminant psittacosis. Crit Care Resusc. 2006;8(1):40-2

81. Petrovay F, Balla E. Two fatal cases of psittacosis caused by Chlamydophila psittaci. J Med Microbiol. 2008;57(Pt 10):1296-8.

82. Rehn M, Ringberg H, Runehagen A, Herrmann B, Olsen B, Petersson AC, et al. Unusual increase of psittacosis in southern Sweden linked to wild bird exposure, January to April 2013. Euro Surveill. 2013;18(19):20478.

83. Sciacca M, Lombard X, Longomba JP, Senterre JM. Psittacosis without pulmonary symptoms at presentation. Rev Med Liege. 2009;64(10):484-7.

84. Senn L, Greub G. Local newspaper as a diagnostic aid for psittacosis: a case report. Clin Infect Dis. 2008;46(12):1931-2.

85. Speelberg B, Heddema ER, Janssen N, Scholtes BMJ, van Vliet ECJ, Verduin CM. Chlamydia psittaci pneumonia with septic shock and hypoxic respiratory failure. Neth J Crit Care. 2014;18(5):18-22.

86. Spoorenberg SM, Bos WJ, van Hannen EJ, Dijkstra F, Heddema ER, van Velzen-Blad $\mathrm{H}$, et al. Chlamydia psittaci: a relevant cause of communityacquired pneumonia in two Dutch hospitals. Neth J Med. 2016;74(2):75-81.

87. Sprague LD, Schubert E, Hotzel H, Scharf S, Sachse K. The detection of Chlamydophila psittaci genotype C infection in dogs. Vet J. 2009;181(3):274-9.

88. Tiong A, Vu T, Counahan M, Leydon J, Tallis G, Lambert S. Multiple sites of exposure in an outbreak of ornithosis in workers at a poultry abattoir and farm. Epidemiol Infect. 2007;135(7):1184-91.

89. Van Droogenbroeck C, Beeckman DS, Verminnen K, Marien M, Nauwynck H, Boesinghe Lde T, et al. Simultaneous zoonotic transmission of Chlamydophila psittaci genotypes $D, F$ and $E / B$ to a veterinary scientist. Vet Microbiol. 2009;135(1-2):78-81.

90. Vanrompay D, Harkinezhad T, van de Walle M, Beeckman D, van Droogenbroeck C, Verminnen K, et al. Chlamydophila psittaci transmission from pet birds to humans. Emerg Infect Dis. 2007;13(7):1108-10.

91. Verminnen K, Duquenne B, De Keukeleire D, Duim B, Pannekoek Y, Braeckman $L$, et al. Evaluation of a Chlamydophila psittaci infection diagnostic platform for zoonotic risk assessment. J Clin Microbiol. 2008;46(1):281-5.

92. Vorimore F, Thebault A, Poisson S, Cleva D, Robineau J, de Barbeyrac B, et al. Chlamydia psittaci in ducks: a hidden health risk for poultry workers. Pathog Dis. 2015;73(1):1-9.

93. Walter SL, Treloar E, Bahl R. Chlamydia psittaci: an unusual but preventable cause of sepsis in pregnancy. Arch Dis Child Fetal Neonatal Ed. 2014;99: A133.

94. Widgren K, Kjelsø C, Uldum SA, Mølbak K. Outbreak of Chlamydophila psittaci infection (ornithosis) in a pet shop in Denmark. Dansk Veterinærtidsskrift. 2009;92(12):24-7.

95. Williams CJ, Sillis M, Fearne V, Pezzoli L, Beasley G, Bracebridge S, et al. Risk exposures for human ornithosis in a poultry processing plant modified by use of personal protective equipment: an analytical outbreak study. Epidemiol Infect. 2013;141(9):1965-74.

96. Yang J, Ling Y, Yuan J, Pang W, He C. Isolation and characterization of peacock Chlamydophila psittaci infection in China. Avian Dis. 2011;55(1) 76-81.

97. DeGraves FJ, Gao D, Hehnen HR, Schlapp T, Kaltenboeck B. Quantitative detection of Chlamydia psittaci and $\mathrm{C}$. pecorum by high-sensitivity real-time PCR reveals high prevalence of vaginal infection in cattle. J Clin Microbiol. 2003;41(4):1726-9.

98. Jencek JE, Beaufrere H, Tully TN Jr, Garner MM, Dunker FH, Baszler TV. An outbreak of Chlamydophila psittaci in an outdoor colony of Magellanic penguins (Spheniscus magellanicus). J Avian Med Surg. 2012;26(4):225-31.

99. Kaleta EF, Taday EM. Avian host range of Chlamydophila spp. based on isolation, antigen detection and serology. Avian Pathol. 2003;32(5):435-61.

100. Osman KM, Ali HA, ElJakee JA, Galal HM. Chlamydophila psittaci and Chlamydophila pecorum infections in goats and sheep in Egypt. Rev Sci Tech. 2011;30(3):939-48.

101. Osman KM, Ali HA, ElJakee JA, Galal HM. Prevalence of Chlamydophila psittac infections in the eyes of cattle, buffaloes, sheep and goats in contact with a human population. Transbound Emerg Dis. 2013;60(3):245-51.

102. Song L, Li Y, Liu G, He J, Zhu H, Duan Q. Genotyping of Chlamydophila psittaci strains derived from avian and mammalian species. Vet Res Commun. 2009;33(6):577-80.
103. Knittler MR, Sachse K. Chlamydia psittaci: update on an underestimated zoonotic agent. Pathog Dis. 2015;73(1):1-15.

104. Ostermann C, Ruttger A, Schubert E, Schrodl W, Sachse K, Reinhold P. Infection, disease, and transmission dynamics in calves after experimental and natural challenge with a Bovine Chlamydia psittaci isolate. PLoS One. 2013;8(5):e64066.

105. McGuigan CC, McIntyre PG, Templeton K. Psittacosis outbreak in Tayside, Scotland, December 2011 to February 2012. Euro Surveill. 2012;17(22).

106. Wallensten A, Fredlund $H$, Runehagen A. Multiple human-to-human transmission from a severe case of psittacosis, Sweden, January-February 2013. Euro Surveill. 2014;19(42).

107. Sachse K, Laroucau K. Avian chlamydiosis: two more bacterial players discovered. Vet J. 2014;200(3):347-8.

108. Anonymous. Zoosanitaire toestand in België [web page]. Federaal Agentschap voor de veiligheid van de voedselketen, FAW; 2015 [updated 10/16/2015]. Available from: http://www.favv.be/dierengezondheid/ zoosanitaire-belgie/. Cited 16 Nov 2015.

109. Greco G, Corrente M, Martella V. Detection of Chlamydophila psittaci in asymptomatic animals. J Clin Microbiol. 2005;43(10):5410-1 author reply -1.

\section{Publisher's Note}

Springer Nature remains neutral with regard to jurisdictional claims in published maps and institutional affiliations.

\section{Ready to submit your research? Choose BMC and benefit from:}

- fast, convenient online submission

- thorough peer review by experienced researchers in your field

- rapid publication on acceptance

- support for research data, including large and complex data types

- gold Open Access which fosters wider collaboration and increased citations

- maximum visibility for your research: over $100 \mathrm{M}$ website views per year

At BMC, research is always in progress.

Learn more biomedcentral.com/submissions 